\title{
OBSERVATIONS OF A RILL EXTENDING THROUGH THE LUNAR VALLEY OF THE ALPS
}

On the night of April 23, 1904, while showing the regular Saturday night visitors the Moon through the 36 -inch refractor, I noticed a rill at several points in the Alpine Valley. The seeing was too poor to make satisfactory observations, but at times the rill could be glimpsed for nearly the whole length of the Valley.

Following are the notes concerning it, made on April 23d and subsequently:

1904 April $23,8^{\mathrm{h}} 30^{\mathrm{m}}$ P.S.T. Moon's age, $8^{\mathrm{d}} 6 \frac{1}{2}^{\mathrm{h}}$.

36 -inch refractor, power 270 .

Rill extends the entire length of the Valley and very nearly in the middle. Not visible continuously, owing to the changeable seeing, but unquestionable when image is steadiest.

1904 April $24,8^{\text {h }}$ P.S.T. Moon's age, $9^{\text {d }} 6^{\text {h }}$.

12 -inch refractor, powers $150,300,500$.

Seeing 3. No trace of rill with power of 150 . Rill suspected at several points with power of 300 , but not certain. Five hundred power too high.

1904 May $6,16^{\mathrm{h}} 30^{\mathrm{m}}$ P.S.T. Moon's age, $21^{\mathrm{d}} 14^{\mathrm{h}}$.

36 -inch, power 520 .

Moon's age too great, no trace of rill. Seeing 1-2.

1904 May $22,9^{\text {b }}$ P.S.T. Moon's age, $7^{\text {d }} 18^{\text {h }}$.

36 -inch, powers 270 and 520 .

At moments can glimpse rill in middle of valley. Sketch.

1904 May $23,7^{\mathrm{h}} 35^{\mathrm{m}}$ to $8^{\mathrm{h}} 30^{\mathrm{m}}$ P.S.T. Moon's age, $8^{\mathrm{d}} 17^{\mathrm{h}}$.

36 -inch, power 520 .

Rill certainly not wider than micrometer wire, which is one-tenth second. On the Moon this corresponds to a width of six hundred feet.

Cannot detect rill at western end of Valley. Four gaps at A, B, C and D. Seeing poor, 2. The south side of rill is in shade, whereas the north side is very bright. The faintest portions of the rill are not more than half the width of the micrometer wire. The rill immediately west of Plato was compared with the rill in the Alpine Valley. The former was conspicuous at all times, the latter was entirely obliterated except at the moments of best seeing. Sketch.

1904 June $4,16^{\text {b }}$ P.S.T. Moon's age, $22^{\mathrm{d}} 1^{\text {h }}$.

36 -inch, power 520. Seeing 3.

Moon too old. Valley of the Alps in shade, except floor at eastern end. Rill can be traced across this region.

1904 July $2,16^{\text {h }}$ P.S.T. Moon's age, $19^{\mathrm{d}} 15^{\mathrm{h}}$. 36 -inch, power 520 .

Seeing is not good enough and the Moon is not old enough to determine the existence of the rill at the four critical points. Rill can at times be seen for most of its length.

1904 August $30,15^{\mathrm{h}} 30^{\mathrm{m}}$ to $17^{\mathrm{h}} 30^{\mathrm{m}}$ P.S.T. Moon's age, $19^{\mathrm{d}} 23^{\mathrm{h}}$. 36 -inch, power 520 .

Rill at $\mathrm{A}$ well seen and is continuous-almost as distinct as to the west of the gap. Cannot trace rill through gap B, but there is a very minute crater about midway of the gap. Suspected the rill to cross the gap through this small crater, but cannot be certain of it.

The entire invisibility of the rill at $A$ on previous occasions and its distinctness tonight, as well as the reverse in the region from $\mathrm{B}$ to $\mathrm{D}$, (especially from $\mathrm{C}$ to $\mathrm{D}$, where absolutely no trace of the rill is to be seen tonight) emphasizes the dependence for visibility of many lunar markings on illumination. The two small craterlets in gap B, so well seen tonight, were invisible on former occasions. Sketches.

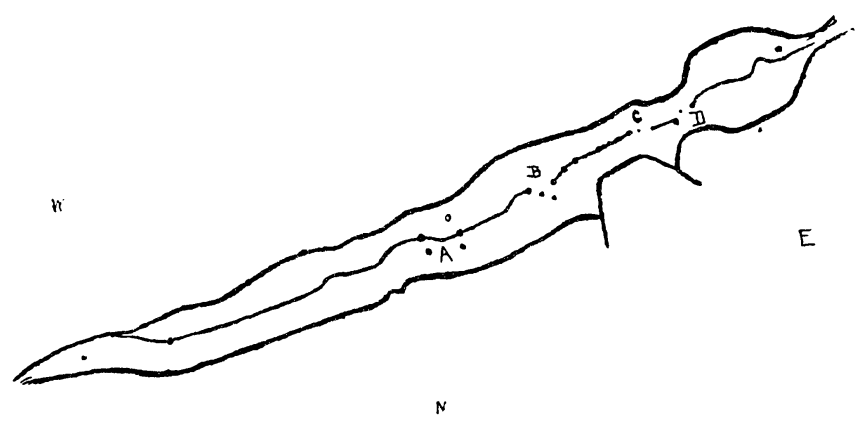

Rill in Valley of the Rlps

The accompanying drawing is compiled from all the sketches. No attempt has been made to include details except such as are connected with the rill, or craterlets very near to it. Attention may be called to the great number of craterlets strung along the rill in some regions and to the fact that at all the gaps the rill terminates in craterlets.

It is not improbable that by observing this object diligently under good conditions, the rill would be found to cross the three short gaps.

I have examined a number of the negatives of this region of the Moon, taken with the 36-inch refractor, especially those taken with an enlarging lens, but fail to find any trace of the rill upon them.

October 16, 1904. 